\title{
Ten years of experience from interactive ergonomics projects
}

\author{
J., Eklund ${ }^{a}$ and J., Karltun ${ }^{\mathrm{b}}$ \\ ${ }^{a}$ Division of Ergonomics, School of Technology and Health, Royal Institute of Technology, KTH, Alfred Nobels \\ Allé 10, SE-141 52 Huddinge, Sweden

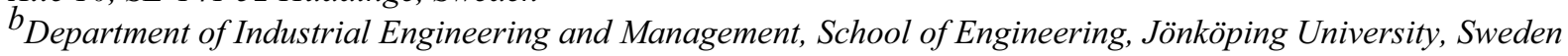

\begin{abstract}
This paper highlights experiences from ergonomics projects, applying an interactive research approach. The aim of this paper is to summarise experiences from seven interactive ergonomics projects with the aim to improve ergonomics and organizational performance jointly. Results from these seven projects were analysed with a model for assessing sustainable change, including the factors active ownership, professional management, competent project leadership, and involved participants. All factors were found giving support to impact and sustainability of the change projects. However, the role of the researcher is difficult and demanding.
\end{abstract}

Keywords: learning evaluations, change, implementation, multidisciplinary

\section{Introduction}

Action research is an established approach to support change and development processes. It has provided valuable knowledge when studying local change in companies and organisations, not the least within the working life research field. It has, however, been criticised for not producing generalised research based knowledge and theories to the extent that could be expected considering the resources used. Some of the problems that have been discussed [1,2] are that:

- the researcher gets an important role in the development, which creates difficulties in the long-time perspective

- there is a risk that the values and the close involvement of the researcher make a critical analysis difficult, also known as the dual task problem

- the focus may often end up on managing the local change process rather than on general understanding and theory development

- large resources are needed in terms of time and effort spent facilitating local change

- the demands on the competences of the researcher are very high in terms of both man- aging the change process including conflicts of interest, and at the same time performing research

- legitimacy in the academic world is low due to the involvement of the researcher

In order to overcome some of these difficulties, the concept of interactive research was proposed [1]. It emphasises that the researcher should not be responsible for the development work, but should be more of a researcher with the main focus on creating new knowledge. The aim for the researcher is to provide theory based analyses that can contribute to a long term theory development which also are relevant for the practitioners. In order to obtain this, the participants or practitioners are involved in these analyses as well as in actions that triggers those activities or analyses. The ambition is to create joint learning processes involving both the researchers and the practitioners, where these are interacting during the whole development process, from definition of the problem to the dissemination of the results. A model describing interactive research projects is shown in figure 1. 


\section{Figure 1. The CMTO model for interactive research (Ellström et al., 1999).}

This interactive research approach has been applied in social science research. One of the difficulties experienced is the difficulties to find persons good at both running projects and producing research and having an independent role.

When performing interactive projects there is a strive to obtain the following aspects:

- Create a high level of participation as well as time and resources to participate

- Create trust and an open atmosphere in the interactions to enable a close and critical discussion

- Document all activities

- Continuous and rapid feedback and discussions of the (documented) development process

- Show similarities and dissimilarities between different cases to improve learning

- Relate experience to earlier research

- Develop concepts and models for joint creation of new knowledge

The characteristics of an interactive approach make it suitable for ergonomics change projects. The value and shortcomings of participatory ergonomics is well known. The aim of this paper is thus to summarise experiences from seven interactive projects with the aim to improve ergonomics and organisational performance jointly.

\section{The ergonomics change programmes}

The seven projects that this paper is based upon were performed mainly during the last 10 -year period. One project was a product development project, in which the ergonomics of fork lift trucks were developed and improved. The second was an interactive intervention among postmen, and the third focussed recycling centres and the personnel there. The fourth was an industry intervention in the meat cutting industry, and the fifth was an interactive evaluation of 18 projects performed with the intention to improve health among employees in the public sector. Finally, the sixth and the seventh were learning evaluations of manufacturing companies introducing Lean production and public organisations introducing Lean in their organisations.

The researchers input in time resources varied from almost 10 man-years to three man-years. The researcher teams were multidisciplinary in all cases. Also the design varied substantially between the projects $[3,4,5,6]$. The reasons for the organisations to get involved were different, e.g. an internal desire to improve, external pressure to improve working conditions or organisational performance in conjunction with working conditions. The general character of these projects was that they were participative and interactive. They aimed at improving ergonomics, and the basic assumption was that the projects must consider working conditions and organisational performance simultaneously, in order to make impact on the organisations. The unions were involved in all projects except the product development one.

The projects were assessed with interviews, questionnaires, documents, observations and notes from analysis seminars. Such data was also collected from internal reports and from official publications [4, 5, 7]. The collection of the background material provided the basis for a holistic analysis according to a model for sustainable change. The factors included in the model are active ownership, professional management, competent project leadership, and involved participants.

\section{Findings}

All projects followed different trajectories. This means that there was substantial planning, negotiation and replanning in all projects. Thus, the consequence was that limited experience in organising the different projects could be reused, but it also meant that participation in planning and preparing the projects was high. The complexity of the projects is another general finding, which means that it was a resource demanding job to manage and to get an overview of them. One difficulty present in all projects was that the practitioners were not familiar with interactive research. It took time to make them familiar 
to the methodology and to make them accept that the activities such as analysis seminars were activities for the benefit of both practice and research.

In several of the projects, sub groups were formed to which different tasks were assigned. These sub groups were often active on different organisational levels. This was an advantage since broader participation and multilevel impact could be accomplished in the organisation that way.

Union participation enhanced employee acceptance and participation in project activities. Also, the projects and their results became more legitimate. Management interest and union interest were often supporting one another but not always. Union representation in steering groups was also important for communication and interest in the projects. Management and union roles concerning e.g. proactiveness and continuation varied between the projects.

The holistic analysis of the projects confirmed that ownership of the projects is crucial for their impact and sustainability. Projects approved of and supported by top management in conjunction with the unions had highest involvement and impact. During periods of stronger top management and union support, project activities were given more emphasis and impact. Also, if external stakeholders exerted pressure on the organisation, e.g. the safety inspectorate, this could have a strong enhancing function.

Regarding professional management, it was evident that management making use of clear and visible processes and actively working to demand results and information from the project was related to better impact, visibility and involvement. When managers showed in action that they supported the projects, the signals sent to the rest of the organisation improved project results.

The third factor, competent project leadership deals with the ability of the project leader in the organisation to organise the project activities. This task was important in order to keep high priority of the present project in relation to other parallel projects and activities. In times of difficulties, the project leader needed to find new ways to handle the problems and to unite the project members.

Finally, the fourth factor, involved participants was also crucial for impact and sustainability. When employees lost interest for a project, it got insufficient legitimacy and low priority. In the projects that managed to obtain a combination of representative participation at a higher level as well as broad direct participation, legitimacy, impact and sustainability was highest.

\section{Discussion}

Ideally, there should be a clear division of roles between researchers and practitioners. This was not easy to obtain in all cases. There were events when some project leaders did not perform their tasks, and the researchers had to step in and help out the situation. Some projects developed in a way that the researchers needed to shift between different roles, such as supporting project leaders or confronting them. Sometimes the researchers were expected to be experts and more or less had to take that role.

In several cases it became evident that too few persons in the organization felt ownership of the project. If they changed jobs, the project could be closed down by the organization, since there were no persons left defending the project in the organization. Consequently, the contacts within the organisation need to be broad in order to improve sustainability.

Another factor that was seen was that the social relationships are very important in order to market and defend the project within the organization. Some project leaders had good social contacts with top managers and had a dialogue around the projects. These project leaders used the opportunity to inform about and give motives for the projects, thereby winning better support for the projects. However, broad information / knowledge dissemination is needed, not only with top managers but also with employees, middle managers and unions. Ability to communicate positively with all stakeholders improved project impact and sustainability. Also pressure from unions, authorities or other external stakeholders support sustainability and impact further.

There are also several contradictions built into the performance of interactive research projects within the field of ergonomics:

The ergonomists aimed at improving health and wellbeing, but their proposed solutions were not implemented unless they also improved productivity or quality. That meant that the ergonomist needed to make a better job than the production engineer. Are those demands unreasonable?

The interactive researcher needs to master different roles not only as researcher but sometimes also as consultant, participant, expert, facilitator, or even as practitioner. Is it reasonable that an ergonomist researcher could manage so many different roles and alternate between them in one project? [8].

Holistic ergonomics projects demand expertise in cognition, physical ergonomics and work organisation. Is the field of required expertise too wide, or 
should interactive research projects only be performed by groups of researchers?

Finally, is it possible for a researcher to be critical after long term interaction with an organisation?

\section{Conclusions}

The application of an analysis model for assessing ergonomics projects according to their impact and sustainability seemed to work and could reasonably well predict outcomes of the projects in terms of impact and sustainability. Common factors that impaired the projects were lack of top management and owner support, but also project leaders, representatives and employees not being sufficiently committed. The task for an interactive ergonomics researcher is demanding in several respects. One is the demand to improve health, wellbeing and organisational performance simultaneously. Another is the challenge to master the many different roles that may appear in the same project, and still another one is the need of broad expertise and experience.

\section{References}

[1] Aagaard Nielsen, K., 2006. Action research and interactive research. Beyond practice and theory. Shaker publishing Maastricht.

[2] Svensson, L., Brulin, G., Ellström, P-E. and Widegren, Ö., 2002. Interaktiv forskning - för utveckling av teori och praktik. (Interactive research - for development of theory and practice). Stockholm, Arbetslivsinstitutet.

[3] Nolimo Solman, K., 2002. Analysis of interaction quality in human-machine systems - applications for forklifts. Applied Ergonomics 33(2), 155-166.

[4] Karltun, A., 2007. Forskarstött förändringsarbete i själva verket: att förbättra arbetssituationen för 15000 brevbärare. (Researcher supported change: improving the work situation for 15000 postmen). PhD thesis No 1122, Linköping University.

[5] Engkvist, I.-L., Eklund, J., Krook, J., Björkman, M., Sundin, E., Svensson, R., Eklund, M., 2010. Joint investigation of working conditions, environmental and system performance at recycling centres - Development of instruments and their usage, Applied Ergonomics, 41(3), 336-346.

[6] Svensson, L., Eklund, J., Randle, H., and Aronsson, G., (2007) Interactive Research - an Attempt to Analyse two Change Programmes. International Journal of Action Research, 3(3), 250-277.

[7] Ellström, P-E., Eklund, J., Kock, H., Lindström, L., Melin, U. (1999): Knowledge Creation Through Collaborative Research: An Emerging Model. Paper presented at HSS -99, March 1618 1999, Falun.

[8] Westlander, G. (2006). Researcher Roles in Action Research. Action and Interactive Research. Beyond Practice and theory. Maastricht, Shaker Publishing. 